\title{
Psychological Problems among Instructors of Newly-Established Universities and Corresponding Interventions
}

\author{
Qinglin Shen \\ Dezhou University, Dezhou 253023, China \\ E-mail: sqldzyzz@163.com
}

\begin{abstract}
As the main force in universities' ideological and political work, instructors are responsible for cultivating qualified talents for the whole nation's construction cause. However, they suffer from a variety of psychological problems due to the reasons lying in working mechanism, working content and working ability. This article analyzes their psychological health conditions in newly-established universities and comes up with some psychological intervention methods
\end{abstract}

Keywords: Instructors, Psychological health, Psychological intervention

It is recorded that there had been 208 newly-established general universities which take up nearly $1 / 3$ of the total. It is undeniable that these universities constitute an underdeveloped section in China's higher education due to the great differences in teaching, students' cultivation and the construction of instructors' staff when compared with those with long history, especially instructors who suffer from psychological problems due to some reasons in staff structure, pressure, treatment, future development and so on. With the increased efforts in the evaluation on instructors, higher requirements on them and a severe shortage of instructors in the recent years, instructors have even greater psychological pressure. Therefore, it is of practical significance how to solve their psychological problems in order to cultivate high-quality college students as well as to promote the sound development of school work.

\section{Analysis on Instructors' Psychological Problems}

\subsection{Psychological Puzzle Caused by Self-Orientation}

Due to the lack of a mature system for instructors' staff construction and management in newly-established universities, instructors may find it difficult to position their job correctly. They are expected to both undertake teaching tasks and instruction and management of students, to ask students to obey relevant requirements laid down by the nation and the school and serve as students' good teachers and friends in order to help them to grow up into talents, to educate students to follow necessary requirements as well as offer them with indispensable service and guarantee in their life and study. As a result, they cannot conduct their work according to their opinions or plans sometimes. It is this kind of uncertain and multiple self-roles as well as conflicts in these roles that have led to their puzzle at their job.

\subsection{Psychological Fatigue Caused by Long-Term Pressure}

Here, psychological fatigue means that people are less interested in their job or even bored with it due to restraints of the nerve center caused by constant stress during a long-term job. It is shown in some surveys that nearly $60 \%$ of the instructors in Shandong's newly-established universities claim that they suffer from excessive pressure and have no much interest in their job, which certainly has prevented their passions for exploration and innovation in students work.

\subsection{Psychological Anxiety Caused by Trivial Daily Management}

Psychological anxiety refers to uneasiness without obvious objective reasons or insupportable fear, which can be manifested in constant nervousness. Because of the uncertainty of students work, instructors are stuck in long-term intense condition, failing to relax their state of mind. In our survey among 45 instructors in Dezhou University, almost half of them have the problem of mental nervousness and even some are afraid to answer the phone during the night. Such long-term stress has increased their psychological burdens, hence psychological anxiety. 


\subsection{Feeling of Frustration Caused by Excessively High Expectations}

Feeling of frustration means one is doubtful about his own ability and therefore loses confidence due to his failure to achieve the expected goal. Feeling of frustration may make a person depressed, irritable or even give up himself. Here an instructor's feeling of frustration mainly comes from dissatisfying effect in his education on students, dissatisfaction at his evaluation result or inharmonious interpersonal relationships with his colleagues and so on. Once influenced by such a feeling, instructors tend to show doubt with their working ability and methods and to be overcautious in their work, hence affecting their working effect. If a vicious cycle is formed, their enthusiasm for their work will be directly influenced.

\subsection{Feeling of Loss Caused by the Contrast between Reality and Education}

Instructors serve as the guide on the way of students' growing-up and undertake the task of cultivating qualified talents. However, the strong contrast between reality and education makes them doubtful of the purpose of their education. Due to poor reputation, poor employment and unobvious teaching effect of newly-established universities, instructors have no strong persuasive force when educating students in ideals and beliefs. This gets worse when it comes to those students who have no confidence in their future due to their poor grades, leaving instructors at a loss.

\section{Causes for Instructors' Psychological Problems in Newly-Established Universities}

\subsection{Incomplete Working Mechanism}

Most of the newly-established universities in Shandong Province just learn from other universities' patterns in instructors' staff management since there is no unique instructor management system of their own. First, incomplete stimulation system makes it unlikely for instructors to be treated fairly in interest distribution, treatment, promotion, talent cultivation and utilization, hence non-equivalence between their pains and gains. Second comes the non-equivalence between their rights and obligations. Schools emphasize more of instructors' obligations and their roles in student management while neglecting their proper status in school management, especially department management. Third, incomplete student management system has led to instructors' heavy burdens and unclear duty divisions. In spite of their great efforts, they are unsure about the key points of their work or clear way of thinking. Due to these factors, instructors are suffering from a feeling of imbalance or even anxiety. Such psychological anxiety tends to be worse in difficulties, which may fill instructors with frustration and depression, hence restraining their activity in work as well as their physical and mental health.

\subsection{Constantly-Expanded Connotation and Extension of Students Work}

With the constant development and advance of society, the connotation and extension of students work have been expanded from time to time, which confronts instructors with great challenges. In those newly-established universities, instructors' work is just like a funnel which has most of the functional departments on the top and the instructors on the bottom. Even some call instructors' work a basket into which anything related to students work can be placed. In spite of the partial side of this opinion, it reflects the orientation of instructors' work made by the school. Such constantly-increasing work load has put instructors into overloading operations every day. Gradually, instructors tend to have psychological fatigue which may cause a variety of psychological problems.

\subsection{Differences between Requirement and Ability}

In Stipulations on Instructors' Staff Construction in General Universities (The Ministry of Education 2006 (No. 24), seven major tasks to be undertaken by instructors are laid down, including education in ideal and belief, formation of students' morality, grasp of students' state of mind, efforts in helping poor students, education on employment ideas, teaching of ideological theories, construction of grass-root student leaders' staff and so on. These tasks ask a lot for instructors in political quality, professional quality, working ability, interpersonal relationship and methods of treating others. However, most of them are young teachers who need to get mature through their work. During their work, it is quite inevitable for them to come across some insolvable problems or deviate from the right way of dealing with problems, which causes their feeling of frustration or even doubt about their working ability, hence influencing their development and advance in the future.

\section{Interventions into Instructors' Psychological Problems in Newly-Established Universities}

\subsection{Accurate Comprehension of "Psychological Intervention"}

Psychological intervention is not totally equivalent to that into psychological crisis. The latter means offering proper psychological assistance for individuals in psychological crisis to help them out of trouble while the former refers to a comprehensive prevention system in which a variety of effective methods are used to trail, instruct or intervene instructors in an all-round and multi-level way. This kind of intervention is directed not only 
to the highly-risky groups with psychological problems, troubles or diseases but the whole instructors' staff. It can take effect in the whole process of instructors' work as well as in the case of their psychological problems.

\subsection{Methods for Psychological Intervention}

Psychological intervention system is a systematic project needing coordination among all relevant departments at school to establish psychological intervention plan, to constantly perfect plans for psychological intervention and to instruct psychological intervention in an all-round way.

(1) Establishing instructors' psychological documents. Among newly-recruited instructors, psychological tests should be held and psychological documents should be established to have an overall knowledge of their psychological conditions which should also be an important requirement for recruitment. By establishing psychological documents and having regular psychological tests, we will have an overall understanding of instructors' psychological changes, detect problems and take some preventive measures accordingly.

(2) Organizing psychological health lectures. In view of the problems found in psychological tests, experts can be organized to have lectures in order to solve instructors' psychological problems at various levels and from various angles. These lectures are expected to have pertinence, pragmaticality and vividness and to start off from the reality of instructors instead of dwelling on empty theories.

(3) Establishing professional psychological consultation staff for instructors. Psychological consultation can effectively prevent the eruption of psychological crisis and help instructors out of depression. Taking the differences between instructors' psychological consultation and that of students into consideration, schools should establish professional psychological consultation staff to learn about instructors' actual work, to learn about the causes for instructors' psychological problems, to conduct pertinent instruction and to help instructors with their practical psychological problems.

(4) Establishing a favorable platform for instructors' work. First, preferential policies on instructors' promotion, evaluation and engagement of professional titles should be conducted to provide space for their development; second, their evaluation and assessment system should be perfected in which reasonable evaluation system should be establish according to instructors' working duties, working effect, working attitudes and working researches to fully stimulate instructors' working activity and enthusiasm and to endow them with proper conditions and platforms for their work and space for their development; third, instructors' reasonable demands should be cared for and satisfied and their actual difficulties should be learned about and solved in order to enhance their sense of duty and responsibility. In this way, they will come to realize their own value and the significance of their work, hence being stimulated to achieve their professional development.

(5) Perfecting the tracking on instructors' psychological problems. Schools should keep a close eye on those instructors with psychological problems and take effective measures to relieve their psychological pressure, helping them to get out of psychological depression soon and recover their happy attitudes towards work.

\section{References}

Lin, Zeyu. (2008). An Investigation on University Instructors' Psychological Health Conditions. Journal of Tongling College, 1.

Peng, Yunlong. (2010). On University Instructors' Psychological Problems. Journal of Educational Institute of Jilin Province, 1.

Shang, Jingjun. (2008). Current Situation and Countermeasures of University Instructors' Psychological Problems. Journal of Jilin Tv\& Radio University, 4.

Wang, Donghong. (2008). Analysis and Reflections on University Instructors' Psychological Problems. Rule by Law and the Society, 3.

Wang, Jianxiang. (2000). An Exploration into University Instructors' Psychological Problems. China Adult Education, 9.

Zhu, Lanfang. (2006). Exploration into College Students' Psychological Problems and Crisis Intervention. Journal of Chuzhou Vocational School, 9. 